\title{
Measuring office productivity
}

\author{
T. McDonald* \\ Department of Computer Science, University of the Orange Free State, P.O. Box 339, Bloemfontein, 9300 \\ Republic of South Africa \\ D. W. Conrath \\ Department of Management Sciences, University of Waterloo, Waterloo, Ontario, Canada
}

\begin{abstract}
Many organizations today are caught in the grip of a severe productivity crisis. If there is an urgent need to improve office productivity, there is also a need to be able to measure productivity in a suitable way. All the measures of total office productivity that have been found in the literature, either do not say how to measure the qualitative aspects of the output or how the quantitative and qualitative aspects are to be combined. In this paper a measure is proposed that considers both the effectiveness (quality and timeliness) and efficiency aspects of office output. An overall composite productivity index is provided. We feel that the proposed measure is an advance over current methods of measuring office productivity.
\end{abstract}

Baie organisasies is vandag vasgevang in 'n ernstige produktiwiteitskrisis. Saam met die ernstige behoefte om produktiwiteit te verbeter, gaan die behoefte om produktiwiteit op 'n geskikte wyse te meet. Die bestaande maatstawe van produktiwiteit in 'n kantooromgewing neem nie die kwalitatiewe aspekte van die afvoer, of die wyse waarvolgens die kwalitatiewe en kwantitatiewe aspekte gekombineer moet word, in ag nie. In hierdie artikel word 'n maatstaf voorgestel wat beide die kwalitatiewe en kwantitatiewe aspekte van die afvoer van 'n kantoor in ag neem. 'n Algehele saamgestelde produktiwiteitsindeks word verskaf. Die gevoel is dat die voorgestelde maatstaf ' $n$ verbetering is op huidige metodes om produktiwiteit in die kantooromgewing te meet.

* To whom correspondence should be addressed

\section{Introduction}

Many organizations today are caught in the grip of a severe productivity crisis. One of the reasons for this is the continually rising costs associated with the white collar work-force. Some economists forecast that if office costs are allowed to continue rising at the current rates, they will double in the next six years (CPRG, 1981). Nobody in business can absorb such an increase.

Surveys conducted in the U.S. (Abraham, 1981) show that the cost of compensating office workers account for more than half of the costs of offices. Of these compensation costs, more than $75 \%$ are attributed to the principals - executives, managers, and professionals. It is obvious where productivity improvement is most needed. If these rising costs do not go hand in hand with productivity improvement, the consequences would be high inflation, high unemployment, and a generally lower standard of living. This presents a real challenge to management today.

Office support technology (e.g. electronic mail, teleconferencing, decision support systems, management information systems, etc.) is being introduced to help meet this productivity challenge. There is widespread agreement among leaders in the information processing industry that this technology is essential for improving the productivity of organizations, and that those organizations that expect to have a favourable competitive and economic position in the coming years must take advantage of it (Diebold, 1980).

If there is an urgent need to improve productivity, there is also a need to be able to measure productivity in a suitable way. At a minimum one needs to justify the introduction of office support systems. Many attempts are reported in the literature. Measures of productivity have traditionally focused on manufacturing. These have been designed to measure the quantitative aspects of the output, and are only appropriate for lower-level standardized office tasks. For more complex and subjective tasks such as those of the principals, quantitative measures alone are insufficient. We need measures that involve the qualitative aspects as well, considering the nature of many office tasks. What we require is the ability to measure total office productivity. As yet, there exists no methodology to measure office productivity in such a comprehensive way.

All the measures of total office productivity that have been found in the literature, either do not say how to measure the qualitative aspects of the output or how the quantitative and qualitative aspects are to be combined. This paper is an attempt to overcome this deficiency. Before our proposed method is given, existing productivity measurements will be reviewed and their shortcomings discussed.

\section{Definitions of productivity}

Traditionally, productivity is defined as the ratio of outputs to inputs (Strassman, 1981).

Productivity $=\frac{\text { Output }}{\text { Input }}$

This way is useful when the office environment and job functions remain unaltered before and after the introduction of office equipment. 'If neither the inputs nor the outputs are in any way altered qualitatively, then a decrease in the cost of input (e.g. labour savings) or an increase in the rate of output (e.g. production 
improvement) will yield a positive increase in productivity' (Strassman, 1981). Because a wellconducted design and implementation of an office support system will most surely change an organization, in a quantitative as well as a qualitative way, this approach is not appropriate to measure total office productivity.

The above definition considers only the efficiency aspects of the productivity. A possible way to remedy this is to define productivity as (CPRG, 1981):

\section{Productivity $=$ Efficiency $\times$ Effectiveness}

Effectiveness as used in the above formula is considered to be 'doing the right thing'. Efficiency is considered to be 'how well we are doing whatever it is that we do'. Efficiency and effectiveness are measured on a scale of $1-10$ by means of questions of the form: " ....... how effective/efficient do you think your department is now?' (CPRG, 1981). This surely is much too subjective to be of much value to management.

Tapscott (Tapscott, 1982) has indicated that to view productivity as simply a relationship between the quantity of the input and the quantity of the output within a given production unit is not sufficient. He observed that the products of office work can be improved both in terms of their quantity (efficiency) and quality (effectiveness). That is:

Productivity $=\frac{\text { Output (quantity and quality) }}{\text { Input (quantity) }}$

This formula has both efficiency and effectiveness dimensions, which we feel is a move in the right direction. However, Tapscott gives no indication of how to measure the quality of the output, nor how the quantity and quality should be combined.

Hershey (1982) defined office productivity as: 'yielding useful, needed, and high-quality products or services within an acceptable time period, while minimizing use of capital and personnel resources and considering the affect of interrelated activities and personnel upon each other'. He considered this as a measure of total effectiveness rather than efficiency. He gave no indication of how to compute the productivity from this definition, nor how to measure the effectiveness factors.

Kettinger (1983) proposed that two types of output indicators should be developed. The first is the traditional method for productivity, to be used when studying quantitative output. The second is an overall effectiveness criteria that should be used when studying those office products and services whose value is more subjective. However, these issues should not be separated. The qualitative aspects should be taken into consideration when computing any sort of index of office productivity.

Everett, Herschauer \& Ruch (1981) proposed a quantity productivity ratio (the traditional productivity ratio of labour output over labour input) and a quality productivity ratio of the form:

Quality-productivity $=\frac{A}{p U+c E}$

Where $A=$ number of units acceptable and free of errors; $U=$ number of units processed; $E=$ number of units subject to correction procedures; $p=$ processing cost per unit; and $c=$ cost per unit for correction processing.

In this form the dimensions are the number of 'good' units produced per dollar spent to produce and correct. Even though this formula provides for quality measurement, it has application only in a market or production environment where 'acceptable' units can easily be identified. This is rarely the case for the output of most offices. There the outputs are mostly acceptable even though they could have been 'better'.

Strassman (1981) suggested that information productivity has two meanings. One addresses the internal efficiency with which a standard office task is carried out. The other is effectiveness, which is determined by the performance, quality, responsiveness, and right scope of the output. The effectiveness productivity is computed as the ratio of value added to overhead labour costs. Value added is measured by removing from total sales revenue all those expenses that represent purchases. Even though the effectiveness productivity measure is valuable by itself, it is used separate from the efficiency measure.

Thor (1983) suggested that the nominal group technique be used to design productivity measures. By weighting the different measures found in this way, an overall, composite productivity measurement index can be constructed. Some of the components of this index might be representative of quality, timeliness, and other factors that cannot be included in a raw efficiency measure. The idea of a composite index is interesting and will be adopted by our proposed measure as well. The only problem with the work of Thor is that he is constructing an overall performance index and not a productivity index.

Stabell (1982) proposed a framework based on microeconomic production theory for empirical research on the effects of office technology. The office is seen as an information-processing activity. Information processing is contrasted to realization activities, and the firm is defined as a set of information-processing and realization activities. The technical efficiency (a measure of the degree to which a firm is producing according to best practice) of realization activities is proposed as a measure of office productivity.

This review covers, to the best of our knowledge, most of the office productivity measures that are reported in the literature. They are valuable in that they show different aspects that one might consider when measuring productivity. To summarize: a comprehensive 
measurement technique should measure both efficiency and effectiveness factors. The effectiveness factors concern (e.g. see Hershey, 1982): quality, timeliness, usefulness, need, and interunit impact. All the factors should be combined into one formula to give an overall productivity measurement. As yet, no such formula exists. In what follows an attempt is made to develop such a measure for total office productivity.

\section{Proposed measure}

The following formula is suggested as a measure of total office productivity:

$$
\text { Productivity }=\frac{\sum_{i}\left(N_{i} Q_{i} T_{i} W_{i}\right)}{\text { Total costs }}
$$

Where $i$ goes from one to the total number of different outputs; $N_{i}=$ quantity of output $i ; Q_{i}=$ weight of the quality factor for output $i ; T_{i}=$ weight of the timeliness factor for output $i ; W_{i}=$ weight to change to dollars the value of output $i$.

It is clear from the above formula that both the efficiency and effectiveness factors are considered. Only quality and timeliness as measures of effectiveness are included, although the formula can be extended to include other qualitative measures as well. The reason why factors such as usefulness, need, and interunit impact are excluded is that they are likely to be strongly correlated with quality and timeliness. For example, output of low quality typically is useless; output that is not received in time is not likely to be needed any more, and the interunit impact is most probably related to the quality and timeliness of the output. Furthermore, our use of the weights in the productivity formula implies that the 'modifiers' be independent of each other. If they are not, their interdependence would have to be factored out, which in turn would result in substantial problems of measurement.

The effectiveness factors are used to weight the efficiency factor. The purpose of these weights are to increase/decrease the productivity when there is an improvement/deterioration in the quality or timeliness of the output, given that all other factors stay the same. An office can be working very efficiently, yet be completely ineffective at the same time (Tapscott, 1982). Many examples can be given to demonstrate this point, but one will suffice. Consider a Management Information System which generates needed management reports. Unfortunately the formatting of these makes them difficult to read; there are a lot of data and yet too little information. We need a measure that will reflect this discrepancy.

Before we proceed with a discussion of how each of the above factors can be measured, we will explain what is meant by each:

- Outputs. These are 'the goods and services produced

for use outside the unit under study, which are for delivery to the users of the output and which are intended to achieve directly the purpose of the unit under study' (Mundell. 1983). The outputs will be considered to be multi-dimensional. consisting both of efficiency and effectiveness dimensions. The efficiency dimension is the quantity or number of the output. The effectiveness dimension consists of its quality and timeliness.

- Quality. This is the degree to which a product or service conforms to a set of predetermined standards related to the characteristics that determine its value to the recipients and its performance of the function for which it was intended (Everett. et al.. 1981).

- Timeliness. This is the degree to which a product or service is provided when needed to render a decision. complete an operation, or fulfill external obligations (Hershey, 1982).

- Input. This is the total cost in constant dollars necessary to produce the output. Included in this are all costs incurred for automation purposes.

\section{Measurement}

To speak meaningfully about the quantities of office outputs poses a non-trivial task, for we are interested in more than just printed pages or the number of invoices processed. Following a procedure suggested by Mundell (1983), office outputs can be identified by means of a hierarchical delineation of the objectives of an organization. This is continued through lower and lower orders until convenient sized outputs, which are produced for use outside the organization, are obtained. For a complete discussion of this method and some case studies where it has been applied, the reader is referred to Mundell (1983). Once the outputs are identified, a counting system can be installed at the place where the outputs leave the boundaries of the organization.

As mentioned earlier, the ratio of the number of acceptable outputs to the total number produced is not a suitable measure of quality in an office environment. For instance, a badly written report with white-out showing in several places may be 'acceptable'. On the other hand, a neat and well-written report with boldface where needed, nice tables, and graphs is also acceptable. Surely the second report is of much higher quality than the first. What is needed is a measure of quality that will reflect such a difference.

Bair (1982) stated: '.......... the ultimate judge of quality is the recipient of the end-products of the organizational unit'. He also suggested that quality can be measured by subjective judgements from the product's recipients. Following this reasoning, each recipient of the output can be asked to rate the quality of the output by means of a score. The recipient judges the quality according to a set of predetermined standards related to its value and the performance of the function for which it was intended. A score of 100 is assumed to be a standard score. The quality weight can therefore be computed by:

$Q=\frac{\text { Quality score of recipient }}{100}$ 
If several recipients receive the same type of output, the mean value of their score can be used in the formula above.

Timeliness is the degree to which output is provided when needed. If output is provided on time, that output should receive a score of 100 . Output received late would earn a lower score and output received early could earn a higher score. This should be judged separately for every different type of output, because it is possible that output received early could be a disadvantage and output received late, might not be much of a problem. It would depend on the item. The adjustment in the score should therefore be based on the importance of the timeliness for that specific output. The timeliness weight can then be computed by:

$T=\frac{\text { Timeliness score of the recipient }}{100}$

100

The actual determination of the weights requires that the respondents (the recipients of the 'office product') treat them as ratio measures. This suggests that the questions asked ought to reflect this fact. An example of such an approach would be:

- Compared to your expectations, your standards of what is appropriate and acceptable, is the quality of the product received better, worse or the same? If it is either better or worse, what percentage change would you attach to this difference in its value? As examples, is the value of the product enhanced by $20 \%$ because of its superior quality?; or is it worth $25 \%$ less to you because of its poor quality?; or is the product's quality such that its value is equivalent to that which you expect and find appropriate?

So far, we have indicated how to obtain the quantity, quality, and timeliness weights for each type of output. Next the different outputs must be aggregated. The outputs are, however, most often not of one kind and, because we cannot add dissimilar things the outputs must be weighted in some fashion. Mundell (1983) suggested various possibilities: labor hour standards, profit margin, market value, or other weights attached to the output. In our formulation, the outputs are divided by costs and therefore cost data should be used as weights. When using dollar values, special care must be taken because productivity measurements for the same organization, taken over different times, are usually compared. In that case, the dollar values must be reduced to 'constant dollars'.

The last piece of information that is needed to compute the overall productivity is the input. As defined above, this must be total cost: capital costs (including all costs incurred for office support systems) and labour costs. These costs should be obtainable from the administration or accounting departments.

\section{Examples}

Some hypothetical examples will be used to illustrate the impact of the efficiency and effectiveness factors on the productivity calculation.
- Consider an organization that makes no investment in office support systems at all. However, through inspired leadership and better planning some organizational changes are made. This results in an improvement in the quality of customer service. Office productivity is calculated in the manner we have suggested and it shows an increase compared to the productivity calculation before the organizational changes. The reason for the increase is the higher value of the quality factor weight.

- In the context of office support systems, consider one which increases total costs by $25 \%$ (using a realistic and detailed calculation). This is to be done to eliminate the missing of deadlines, which occurs $25 \%$ of the time. And each time the deadline is missed the value of the product drops by $50 \%$. In addition, the overall quality is expected to appreciate by $10 \%$ if the system is used.

Given that 16 units are produced per week, and that each is valued at 100 dollars, and that current costs are 1200 dollars per week, the before and after productivity calculations are as follows:

$$
\begin{aligned}
\begin{array}{c}
\text { Productivity } \\
\text { (before) }
\end{array} & =\frac{12 \times 1 \times 1 \times 100+4 \times 1 \times 0,5 \times 100}{1200} \\
& =\frac{1400}{1200} \\
& =1,167 \\
\begin{array}{c}
\text { Productivity } \\
\text { (after) }
\end{array} & \frac{16 \times 1,1 \times 1 \times 100}{1200 \times 1,25} \\
& =\frac{1760}{1500} \\
& =1,173
\end{aligned}
$$

In other words, the productivity is just about the same with or without the new support technology.

This latter example points out another advantage of the productivity measure. It provides the gross rate of return on office expenses, something which is often calculated for manufactured products but which has been ignored for office work.

\section{Conclusion}

The existing methods to measure office productivity were reviewed. It appears that as yet, no methodology exists to measure office productivity in a comprehensive way. Either the qualitative aspects of the output are not taken into consideration or they are not combined with the quantitative factors.

In this paper a measure was proposed that considers both the effectiveness (quality and timeliness) and efficiency aspects of office output. The effectiveness factors are used to weight the efficiency factor. The quality and timeliness weights are obtained from scores provided by the recipients of the outputs. The quantity of the outputs and the quality and timeliness weights are combined and given dollar values, and then divided by 
total costs, to provide an overall composite productivity index. A few examples were given to demonstrate the effect the effectiveness factors have on the measurement of the productivity. Even though there is still much work to be done, especially the validation of its use in this field, we feel the proposed measure is an advance over current methods of measuring office productivity.

\section{References}

Abraham, S. M. 1981. The impact of office automated systems on the productivity of managers and professionals. AFIPS, Office Automation Conference Digest, 165-175.

Bair, J.H. 1982. Productivity assessment of office information system technology. In: R. Landau (Ed.), Emerging Office Systems, Abex Publishing Corporation, 159-186.

CPRG. 1981. Productivity in the office: Part oneUnderstanding a difficult concept. The Corporate Productivity Research Group Inc., Toronto, Canada.

Diebold. 1980. Measurement and evaluation techniques. The Diebold Group Inc., Park Avenue South, New York.
Everett, E.A., Herschauer, J.C. \& Ruch, W.A. 1981 Productivity and Quality: Measurement as a basis of improvement. New Jersey: Prentice-Hall.

Hershey, G.L. 1982. Let quality count in productivity measurement. Word Processing and Information Systems, p.25.

Kettinger, W.J. 1983. Models of office productivity: What really can be expected. AFIPS, Office Automation Conference Digest, 31-37.

Mundell, M.E. 1983. Improving productivity and effectiveness. New Jersey: Prentice-Hall.

Stabell, C.B. 1982. Office Productivity: A microeconomic framework for empirical research. Office: Technol. People, vol. 1, 91-106.

Strassman. P.A. 1981. Overview of Strategic Aspects of Information Management. AFIPS, Office Automation Conference Digest, 17-28.

Tapscott, D. 1982. Office Automation: A user-driven method. New York: Plenum Press.

Thor, C.G. 1983. Productivity Measurement in white collar groups. In: N. Lehrer (Ed.) White Collar Productivity, McGraw-Hill, 29-42. 